\title{
OP19
}

\section{LIGHT AND BLUE-LIGHT EXPOSURES OF DAY WORKERS IN SUMMER AND WINTER}

\author{
Ljiljana Udovicic et al. \\ DOI 10.25039/x46.2019.OP19 \\ from \\ CIE x046:2019 \\ Proceedings \\ of the \\ 29th CIE SESSION \\ Washington D.C., USA, June 14 - 22, 2019 \\ (DOI 10.25039/x46.2019)
}

The paper has been presented at the 29th CIE Session, Washington D.C., USA, June 14-22, 2019. It has not been peer-reviewed by CIE.

(C) CIE 2019

All rights reserved. Unless otherwise specified, no part of this publication may be reproduced or utilized in any form or by any means, electronic or mechanical, including photocopying and microfilm, without permission in writing from CIE Central Bureau at the address below. Any mention of organizations or products does not imply endorsement by the CIE.

This paper is made available open access for individual use. However, in all other cases all rights are reserved unless explicit permission is sought from and given by the CIE.

CIE Central Bureau

Babenbergerstrasse 9

A-1010 Vienna

Austria

Tel.: +43 17143187

e-mail: ciecb@cie.co.at

www.cie.co.at 


\title{
LIGHT AND BLUE-LIGHT EXPOSURES OF DAY WORKERS IN SUMMER AND WINTER
}

\author{
Udovicic, L. ${ }^{1}$, Price, L.L.A. ${ }^{2}$, Khazova, M. ${ }^{2}$ \\ ${ }^{1}$ Federal Institute for Occupational Safety and Health (BAuA), Dortmund, GERMANY, \\ 2 Public Health England (PHE), Centre for Radiation Chemical and Environmental Hazards, \\ Harwell, Didcot, Oxfordshire, UNITED KINGDOM \\ udovicic.ljiljana@baua.bund.de
}

DOI $10.25039 / \times 46.2019 .0 P 19$

\begin{abstract}
Incandescent and halogen light bulbs for general lighting do not meet new energy efficiency requirements and are gradually being phased out. Newer artificial light sources such as compact fluorescent lights and light emitting diodes (LEDs) provide more energy-efficient alternatives. A question that is sometimes raised is whether exposure to light from new artificial sources could lead to adverse health outcomes. Various studies into the photochemically-induced retinal damage due to extended exposures to blue light have been conducted under very high irradiances.

In our study, we have examined the level of light exposure in everyday working lives. Average indoor and outdoor blue-light irradiance and illuminance of day working hospital employees show that exposure conditions in studies mentioned above cannot be instructive in determining health risks from long-term light exposure from artificial sources for general lighting.
\end{abstract}

Keywords: light exposure, blue-light hazard, blue-light irradiance, light emitting diodes (LEDs)

\section{Introduction}

With the aim of reducing energy cost of lighting, incandescent and halogen light bulbs for domestic, office and industrial general lighting in the European Union (EU), and many other countries, are being phased out in favour of other types of energy-efficient electric lighting alternatives, such as compact fluorescent lights and light emitting diodes (LEDs). The introduction of LEDs as light sources has prompted questions about their photobiological safety and concerns about the possibility of retinal damage due to the blue-light hazard.

The term "blue light hazard" describes acute photochemical damage to the retina. The damage mechanism has an action spectrum known for more than 40 years - the blue-light hazard function $B(\lambda)$ that peaks in the blue region of the visible spectrum at approximately $440 \mathrm{~nm}$ (Ham and Mueller, 1976). The International Commission on Non-Ionizing Radiation Protection (ICNIRP) publishes guidelines recommending exposure limits for the blue-light hazard and various other optical radiation hazards. These limits are deliberately set significantly below the thresholds for tissue damage. The exposure limit values (ELVs) in the Artificial Optical Radiation Directive (AORD, 2006), intended to protect workers from the bluelight hazard and other risks to health from hazardous sources of artificial optical radiation, are based on the ICNIRP guidelines published in 1997 (ICNIRP, 1997) and 2004 (ICNIRP, 2004). In the new ICNIRP guidelines published in 2013 (ICNIRP, 2013), the recommended blue-light hazard exposure limits have not been changed.

In order to assess the exposure, the measured spectral radiance $L(\lambda)$ of a light source at an exposure location has to be weighted by the blue-light hazard function $B(\lambda)$ and summed to give a blue-light effective radiance $L_{\mathrm{B}}$ (expressed in $\mathrm{W} \cdot \mathrm{m}^{-2} \cdot \mathrm{sr}^{-1}$ ). Multiplying $L_{\mathrm{B}}$ by the exposure duration gives the blue-light effective radiance dose, $D_{\mathrm{B}}$, which should not exceed $10^{6} \mathrm{~J} \cdot \mathrm{m}^{-2} \cdot \mathrm{sr}^{-1}$ within a total continuous viewing time of up to $10000 \mathrm{~s}$. If the viewing duration might be longer than $10000 \mathrm{~s}$, the blue-light effective radiance $L_{\mathrm{B}}$ should not exceed $100 \mathrm{~W} \cdot \mathrm{m}^{-2} \cdot \mathrm{sr}^{-1}$. 
For comparison with retinal exposures, the blue-light effective radiance dose limit $D_{\mathrm{B}, \mathrm{ELV}}$ can be transformed into a radiant exposure limit $H_{\mathrm{B}, \mathrm{ELV}}$ by the multiplication with the solid angle that is subtended by the pupil of the eye, $\Omega=0,024 \mathrm{sr}$ (using a pupil diameter of $3 \mathrm{~mm}$ and an effective distance between the pupil of the eye and the human retina of $17 \mathrm{~mm}$; Sliney, 1984). Assuming no transmission loss, the blue-light effective radiant exposure $H_{\mathrm{B}}$ at any given point on the retina should not exceed $24000 \mathrm{~J} \cdot \mathrm{m}^{-2}$ (ICNIRP, 2013). Also, for exposure durations of $10000 \mathrm{~s}$ and above, the blue-light effective radiance limit $L_{\mathrm{B}, \mathrm{ELV}}$ of $100 \mathrm{~W} \cdot \mathrm{m}^{-2} \cdot \mathrm{sr}^{-1}$ can be transformed into the blue-light effective irradiance limit $E_{\mathrm{B}, \mathrm{ELV}}$ of $2,4 \mathrm{~W} \cdot \mathrm{m}^{-2}$.

Lending support to the concerns about the blue-light hazard caused by the artificial light sources are mechanistic studies reporting retinal damage in cell cultures or animal models exposed to high irradiances. However, it is easily shown in the introduction below that the exposures in these studies exceeded the ELVs, and further the data collected in this study for hourly average blue light levels in artificial lighting at work are not comparable to the high irradiances used.

For instance, Chamorro et al. (2013), exposed human retinal pigment epithelial (RPE) cells in vitro to the LED light and showed a decrease in cellular viability and increases in cellular apoptosis, production of reactive oxygen species (ROS) and DNA damage. The RPE cells were exposed to $12 \mathrm{~h} / 12 \mathrm{~h}$ LED light-darkness cycles using blue, green, red and white LEDs. Light exposure for all LEDs is reported as unweighted irradiance* of $5 \mathrm{~mW} \cdot \mathrm{cm}^{-2}$ (equivalent to $50 \mathrm{~W} \cdot \mathrm{m}^{-2}$ ). The important information on the blue-light effective irradiance is lacking, so by the way of example we have calculated it for one of the light sources used in the study, the blue LED (peak wavelength $468 \mathrm{~nm}$, full width at half maximum (FWHM) $30 \mathrm{~nm}$ ). Spectral measurements of a blue LED (peak wavelength $467 \mathrm{~nm}$, FWHM $30 \mathrm{~nm}$ ) in the Optical Laboratory of the Federal Institute for Occupational Safety and Health gave the ratio between the unweighted irradiance and the blue-light effective irradiance of approximately 1,5 . Therefore, the unweighted irradiance of $50 \mathrm{~W} \cdot \mathrm{m}^{-2}$ reported in the study of Chamorro et al. was divided by 1,5 to give $33 \mathrm{~W} \cdot \mathrm{m}^{-2}$ as the blue-light effective irradiance of a blue LED used in this study. Finally, since the radiant exposure equals irradiance multiplied with exposure duration $\left(H_{\mathrm{B}}=E_{\mathrm{B}} \cdot t\right)$, permitted exposure duration can be calculated, showing that in the case of the blue LED, the ELV was exceed in only $12 \mathrm{~min}$. The exposure lasted $12 \mathrm{~h}$, i.e. longer than $10000 \mathrm{~s}$, and also here the ELV was exceeded by a factor of 14 (the blue-light effective irradiance of $33 \mathrm{~W} \cdot \mathrm{m}^{-2}$ divided by the blue-light effective irradiance limit which is for exposure duration of $10000 \mathrm{~s}$ and above constant, $E_{\mathrm{B}, \mathrm{ELV}}=2,4 \mathrm{~W} \cdot \mathrm{m}^{-2}$ ).

Similar analysis could show that the ELV for exposure duration shorter than $10000 \mathrm{~s}$ was also exceeded in the study of Sparrow et al. (2004). In this study the RPE cells in vitro were exposed to blue and green light of wavelengths $430 \mathrm{~nm}$ and $550 \mathrm{~nm}$, respectively, as well as to white light for $20 \mathrm{~min}$. The unweighted irradiance of both blue and green light was $8 \mathrm{~mW} \cdot \mathrm{cm}^{-2}$ (equivalent to $80 \mathrm{~W} \cdot \mathrm{m}^{-2}$ ), and of the white light $246 \mathrm{~mW} \cdot \mathrm{cm}^{-2}$ or $2460 \mathrm{~W} \cdot \mathrm{m}^{-2}$.

In any given 24-hour period, people are exposed to both natural light and light from a range of artificial sources, often simultaneously. The objective of this paper is to examine the level of light exposure in everyday working lives: average indoor and outdoor blue-light irradiance and illuminance levels from measurement data collected by day working hospital employees will be presented. Light exposures presented in this contribution were measured within a joint project of the Federal Institute for Occupational Safety and Health (BAuA) and the Public Health England (PHE). The aim of the project was to determine light exposure from natural and artificial sources with regard to circadian effects in shift-working employees; however light data collected in this project can also be used to respond to other questions.

\footnotetext{
* Note that the use of unweighted irradiance or inappropriately weighted quantities such as illuminance is uninformative, can be misleading and should be avoided.
} 


\section{Methods}

Light exposures were measured by nurses for a week in January 2015 (winter) and a further week in June 2015 (summer) in Klinikum Dortmund (43 subjects) and, concurrently, at Kings College Hospital in London (42 subjects).

24-hour light exposure data were recorded by a commercial actimetry research device Actiwatch Spectrum (AWS, Fig. 1a) (Actiwatch Spectrum, Philips Respironics), discontinued in 2016. The AWS device includes three solid-state photosensors (silicon photodiodes with distinct optical filters). The photosensors detect irradiance (expressed in $\mu \mathrm{W} \cdot \mathrm{cm}^{-2}$ ) in the red, green and blue regions of the visible spectrum, between $350 \mathrm{~nm}$ and $750 \mathrm{~nm}$, and the AWS calculates an estimate of illuminance (expressed in IX) using these measurements. Fig. 1b depicts spectral sensitivities of Actiwatch Spectrum R-, G- und B-photosensors. The AWS devices were calibrated in optical laboratories of the Public Health England and the Federal Institute for Occupational Safety and Health (Price et al., 2013, Udovicic et al., 2016). The blue-light hazard function $B(\lambda)$ was approximated by the signal of the B-photosensor (see Fig. 1b).

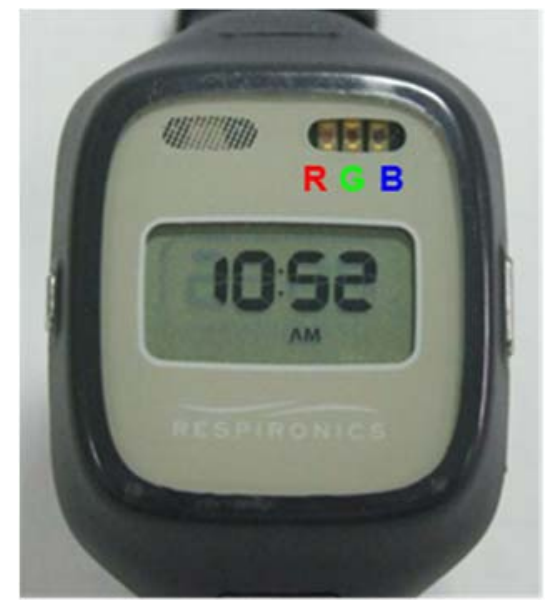

a)

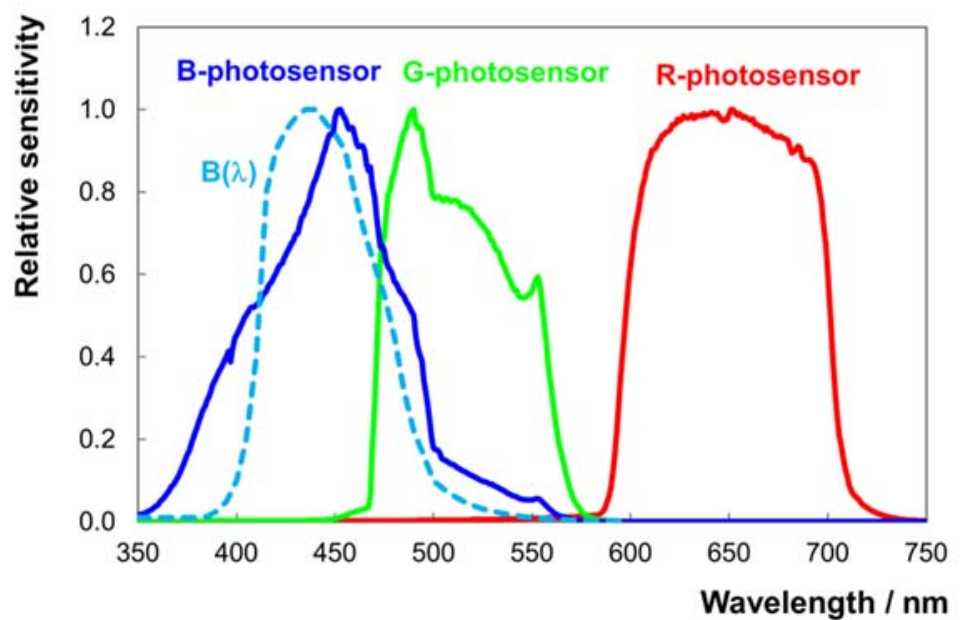

b)

Figure 1 - a) An Actiwatch Spectrum device from Philips Respironics with three photo- sensors for the red (R), green (G) and blue (B) portion of the visible spectrum, b) Spectral sensitivity of Actiwatch Spectrum R-, G- und B-photosensors and action spectrum $B(\lambda)$

The AWS devices were worn as a badge on the upper chest on the outer layer of clothing (Fig. 2) continuously for seven days while awake. When in bed to sleep, they were placed on the bed-side table in order to measure bedroom light levels. As an actimetry device, the AWS also contains accelerometers to detect activity. The activity data were used to identify periods when the device was not being worn and these periods were excluded on the presumption that the personal exposure to light was not being measured.

Participants completed a lighting questionnaire giving information on the light sources in the workplace and at home. Sleep and activity timing diaries were completed including data on time spent indoors (at the workplace, at home) and outdoors (walking, doing sports). Subjects provided written consent, and the data were stored and processed anonymously. 


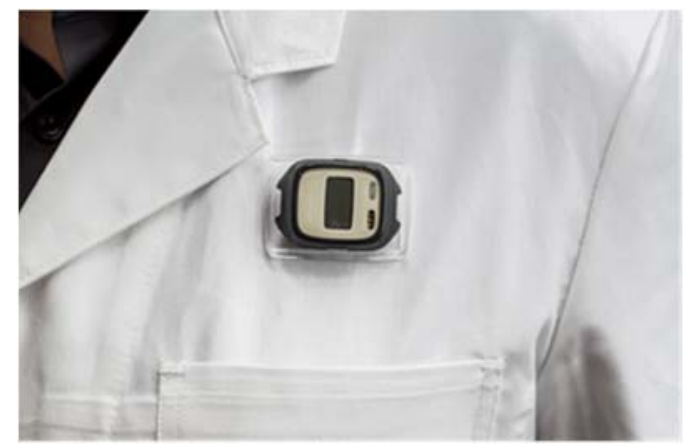

Photo: Uwe Völkner/Photographic Agency FOX

Figure 2 - A chest-mounted Actiwatch Spectrum acquiring personal light exposure, as worn on the outer layer of clothing

\section{Results}

Dortmund and London have the same latitude $\left(51,5^{\circ}\right)$ and the longitude difference is $7,5^{\circ}$; on average sunrises and sunsets take place half-an-hour earlier in Dortmund in Coordinated Universal Time, but half-an-hour later using local clocks. The day working times of the nurses in Germany comprised two shifts (early and late shift from 6:30 to $14: 30$ and 14:30 to 22:30, respectively) compared to two shifts in the UK (short and long day work in London from 09:00 to $17: 00$ and from $07: 30$ to $20: 00$, respectively).

Fig. 3 shows an example of the B-photosensor irradiance (blue-light irradiance) and illuminance measured by a nurse in Germany who worked between January 23 and 29, 2015, only day shifts (two early and one late shift). Measured blue-light irradiance and illuminance have been averaged over an hour. Average hourly blue-light irradiances measured in Germany and the UK in January and June 2015 for different day shifts are shown in Figs. 4 and 5 .

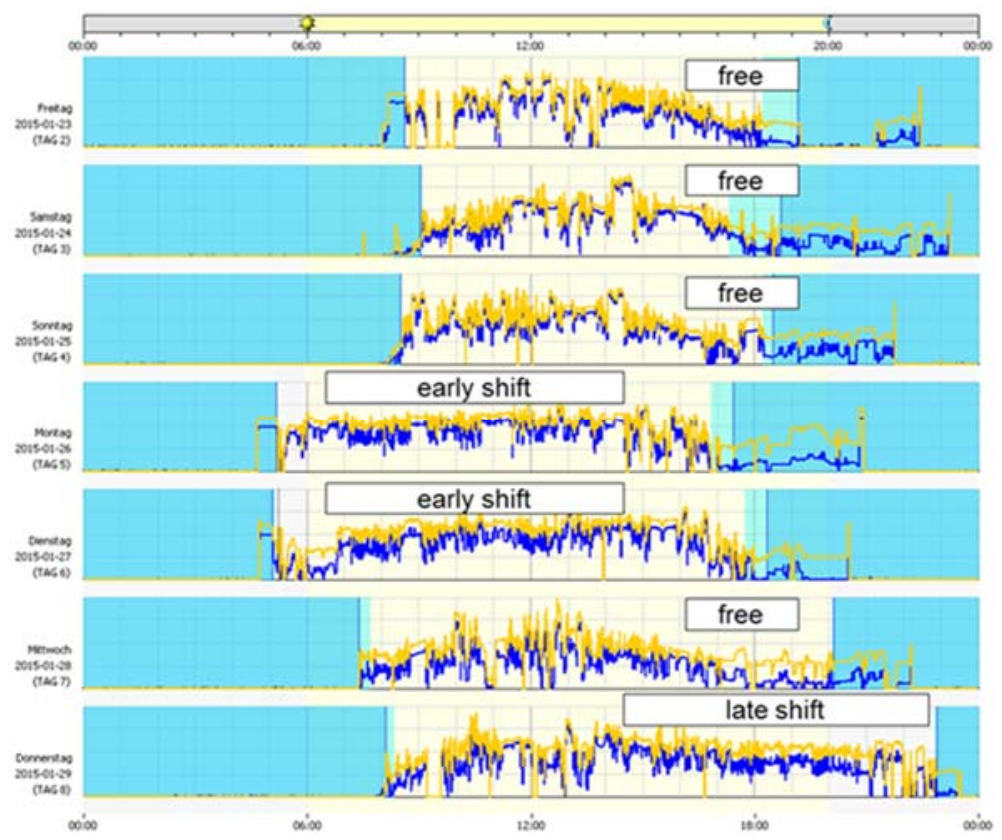

Figure 3 - An example for the blue-light irradiance (blue) and illuminance (yellow) measured by a nurse who worked two early shifts and one late shift between January 23 and 29, 2015 in Dortmund. 


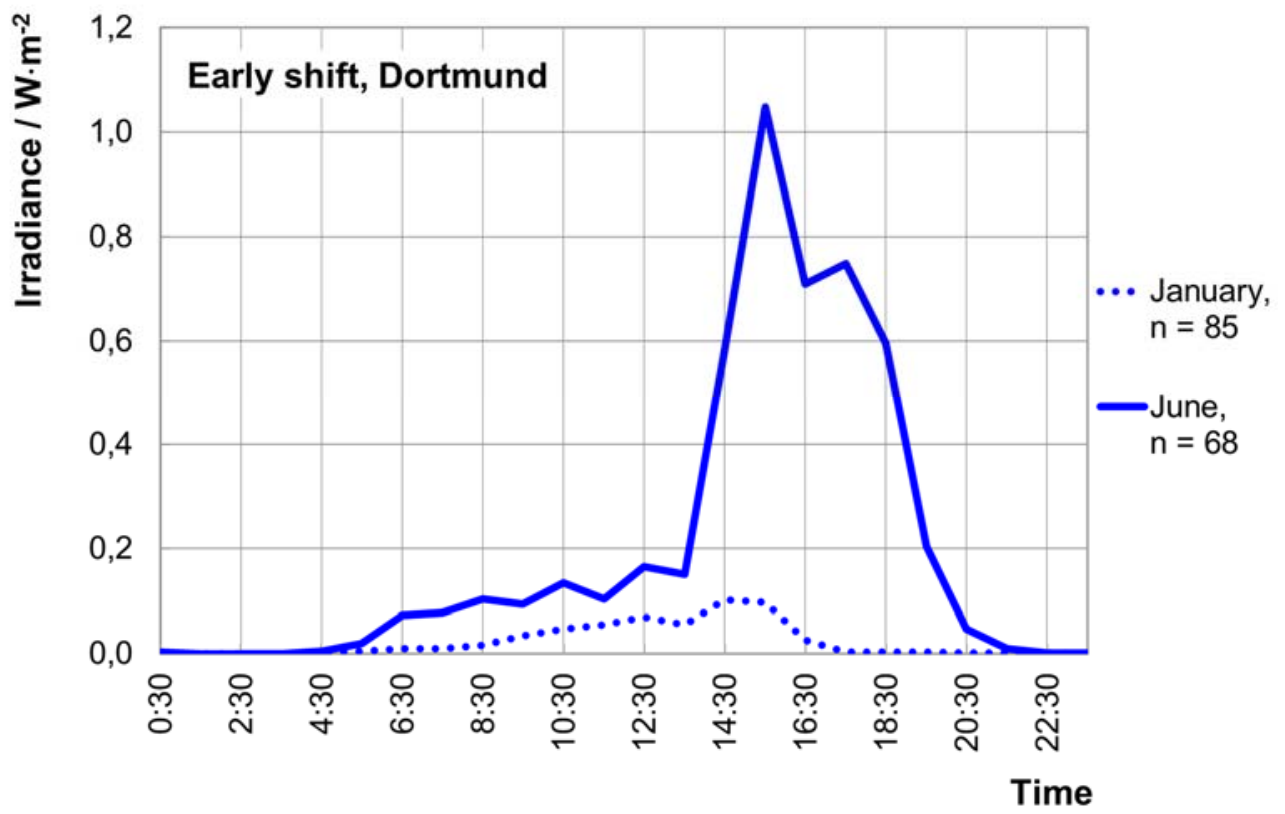

a)

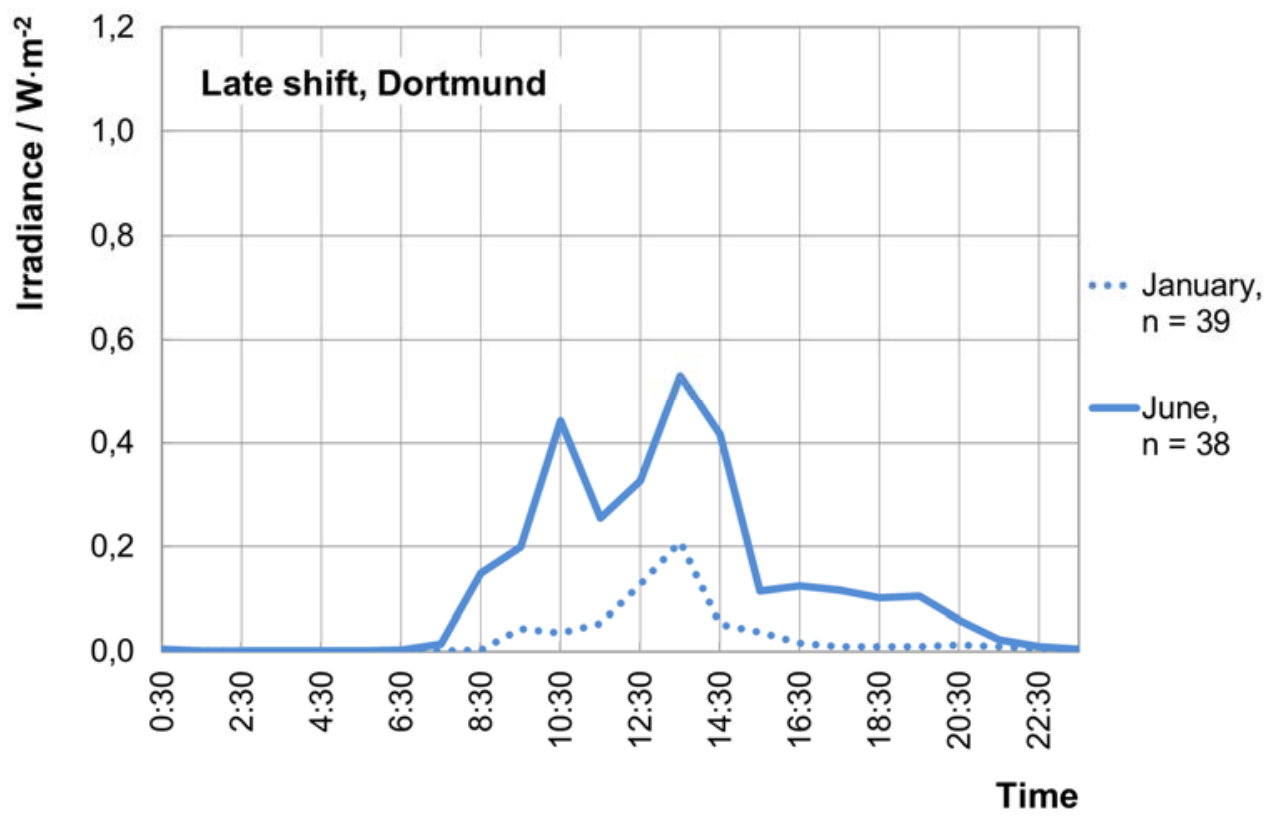

b)

Figure 4 - Average hourly blue-light irradiance measured in Germany in January and June 2015. The number of shifts $\boldsymbol{n}$ includes multiple shifts from some nurses.

a) Early shift in Dortmund, working time 06:30 - 14:30

b) Late shift in Dortmund, working time 14:30 - 22:30 


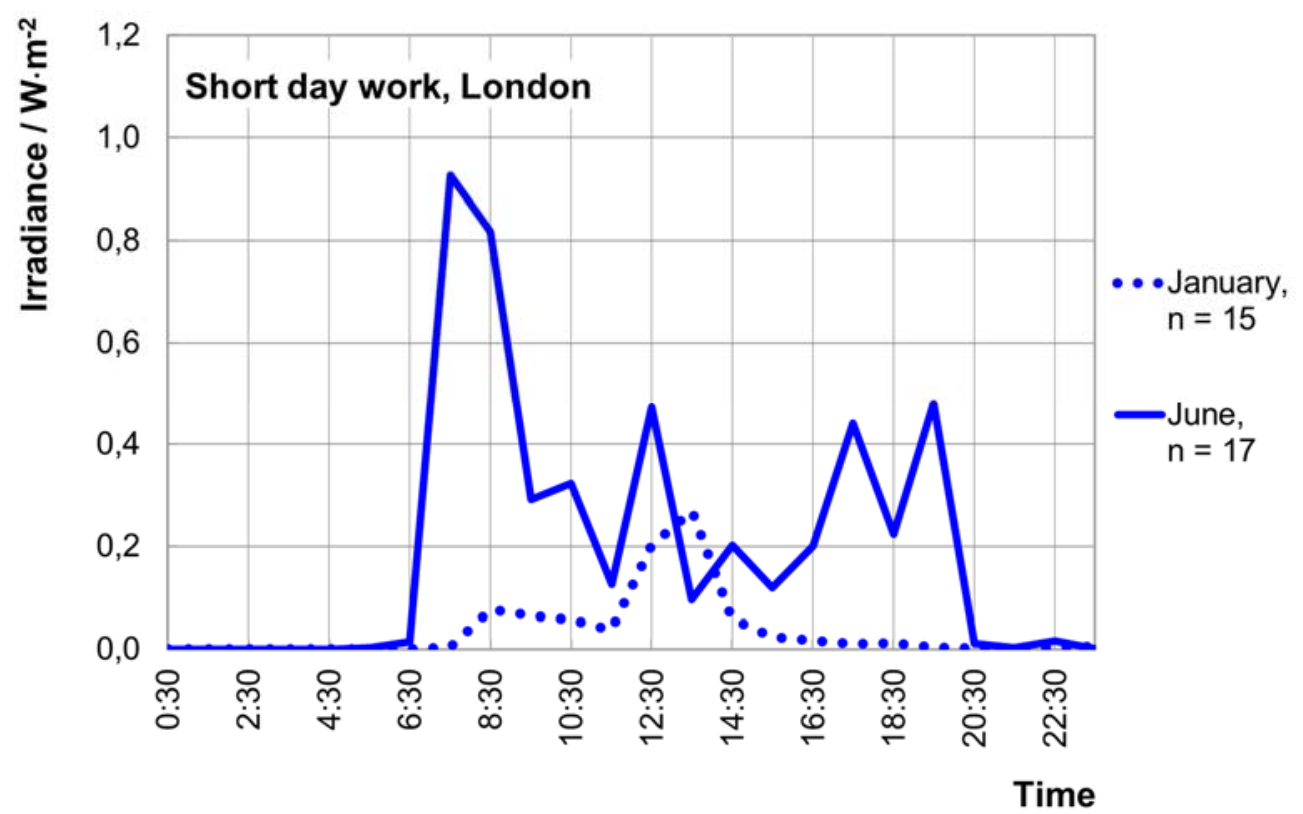

a)

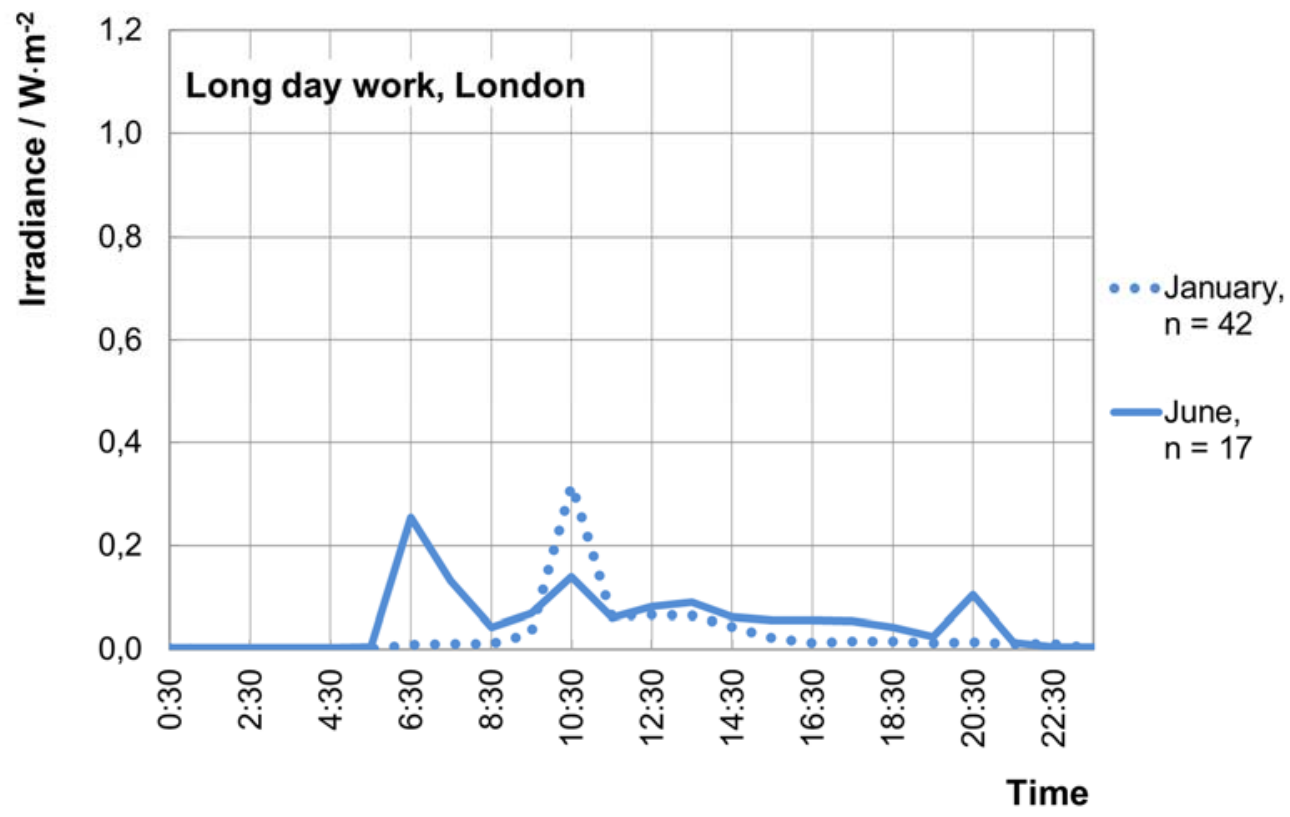

b)

Figure 5 - Average hourly blue-light irradiance measured the UK in January and June 2015. The number of shifts $\mathbf{n}$ includes multiple shifts from some nurses.

a) Short day work in London, working time 09:00 - 17:00

b) Long day shift in London, working time 07:30 - 20:00 
Table 1 - Average hourly blue-light irradiance and illuminance measured in Dortmund (early shift) and London (short day work) in winter and summer for selected times of a day.

\begin{tabular}{|c|c|c|c|c|c|}
\hline & & \multicolumn{2}{|c|}{ Winter } & \multicolumn{2}{|c|}{ Summer } \\
\hline & & $\begin{array}{l}\text { Average } \\
\text { irradiance / } \\
\mathbf{W} \cdot \mathbf{m}^{-2}\end{array}$ & $\begin{array}{l}\text { Average } \\
\text { illuminance I } \\
\text { Ix }\end{array}$ & $\begin{array}{l}\text { Average } \\
\text { irradiance I } \\
\mathbf{W} \cdot \mathrm{m}^{-2}\end{array}$ & $\begin{array}{l}\text { Average } \\
\text { illuminance I } \\
\text { Ix }\end{array}$ \\
\hline \multirow{5}{*}{$\begin{array}{l}\text { Early shift, } \\
\text { Dortmund }\end{array}$} & $\begin{array}{l}\text { At home, } \\
00: 30-04: 30\end{array}$ & 0,0005 & 1,6 & 0,0017 & 3,0 \\
\hline & $\begin{array}{l}\text { At work, } \\
10: 30-11: 30\end{array}$ & 0,0513 & 64,3 & 0,1188 & 528,7 \\
\hline & $\begin{array}{l}\text { Commuting } \\
\text { 14:30 - 15:30 }\end{array}$ & 0,0989 & 186,4 & 0,8147 & 1037,0 \\
\hline & $\begin{array}{l}\text { Outdoor* }^{*} \\
\text { (commuting } \\
14: 30-15: 30 \text { ) }\end{array}$ & 0,3637 & 639,6 & 2,8528 & 5074,7 \\
\hline & $\begin{array}{l}\text { At home, } \\
20: 30-22: 30\end{array}$ & 0,0015 & 7,2 & 0,0194 & 35,6 \\
\hline \multirow{5}{*}{$\begin{array}{l}\text { Short day } \\
\text { work, } \\
\text { London }\end{array}$} & $\begin{array}{l}\text { At home, } \\
00: 30-04: 30\end{array}$ & 0,0001 & 0,4 & 0,0001 & 0,2 \\
\hline & $\begin{array}{l}\text { Commuting } \\
08: 30\end{array}$ & 0,0767 & 125,4 & 0,8180 & 700,7 \\
\hline & $\begin{array}{l}\text { At work } \\
10: 30-11: 30\end{array}$ & 0,0467 & 94,0 & 0,2241 & 265,4 \\
\hline & $\begin{array}{l}\text { Commuting } \\
17: 30\end{array}$ & 0,0098 & 31,0 & 0,4406 & 731,1 \\
\hline & $\begin{array}{l}\text { At home, } \\
20: 30-22: 30\end{array}$ & 0,0027 & 8,8 & 0,0101 & 24,1 \\
\hline
\end{tabular}

* Outdoor values in Dortmund measured on January 14, 15 and 16, 2015; $n=20$.

The average levels of the blue-light irradiance and the illuminance show the effects of

- season (winter, summer),

- selected times of day (night, afternoon, evening),

- being indoors / outdoors, and

- being at workplace / at home.

In general, the average indoor levels of blue-light irradiance measured close to the eyes, including light due to artificial sources, are approximately 200 times lower than the light levels applied in the animal experiments mentioned earlier. As might be expected, the same indoor levels of light exposure are also significantly lower compared with the natural daylight outdoors.

\section{Conclusion}

Average levels of indoor blue-light irradiance from artificial light sources are much lower than the light levels used in some studies aiming to prove that long-term exposure to LED light causes retinal damage. 24-hour exposures (excluding sleep) to indoor blue-light irradiance 
from artificial light sources are also much lower than relatively short exposures to natural daylight outdoor levels. Therefore, we conclude that these studies do not support the hypothesis that long-term exposure from blue light in modern artificial light sources, such as LEDs, used everyday life can cause retinal damage. The dosimetry data add to the evidence in support the Opinion of the Scientific Committee on Health, Environmental and Emerging Risks (SCHEER, 2018) and latest CIE position statement on the Blue Light Hazard (CIE, 2019).

A third paper using animal models (Jaadane et al., 2015) investigated the blue-light hazard using with Wistar rats in vivo exposed to white, green and three different blue LEDs $(473 \mathrm{~nm}$, $467 \mathrm{~nm}$ and $449 \mathrm{~nm}$ ) and reported a damage of the photoreceptors layer after $18 \mathrm{~h}$ of exposure (the dose reported for one of three blue LEDs was $34,2 \mathrm{~J} \cdot \mathrm{cm}^{-2}$, equivalent to $\left.3,42 \cdot 10^{5} \mathrm{~J} \cdot \mathrm{m}^{-2}\right)$. Rats are nocturnal and light averse, with eyes that are smaller and have a much higher pre-retinal transmittance in the blue spectral region. As a result, the interpretation in terms of effects in humans is complex, and Ham and Mueller (1976) explicitly advise against making inter-species comparisons. We consider that when the conditions reported are converted into equivalent human exposures, it is likely that these would also exceed the ELVs.

Indeed, modern general purpose lighting cannot be considered more blue than many established lighting sources, or else the colour of the light emitted would not be visually acceptable. In future, the emissions from sources using ultra-violet or violet LEDs below $440 \mathrm{~nm}$ where visual effects on colour become weaker may warrant further studies, but this study adds further weight against concerns of retinal damage from everyday lighting incorporating blue LEDs.

It is worth noting that the AWS does not measure radiance and the methodology applied is not intended to be a substitute for the optical radiation hazard assessment required by EU legislation concerning the protection of workers from adverse health effects (see Udovicic and Janßen, 2019). It was occasionally observed that AWS saturate at high irradiances. The data were also recorded at 30 -second intervals (thought to be based on sampling approximately every $5 \mathrm{~s}$ to $10 \mathrm{~s}$ ). It is therefore not possible with these data to rule out short exposures that exceed the ELVs.

However, studies have been published that imply risks of adverse health effects under extreme exposure conditions. Combined with measurement data relating to the radiance levels in samples of modern LED lighting and screens (CIBSE, 2016; O'Hagan et al., 2016; Udovicic and Janßen, 2019) the data presented confirm that the studies of the type mentioned above cannot be instructive in determining present day health risks from long-term LED light exposure.

\section{References}

ACTIWATCH SPECTRUM. Philips Respironics: http://www.usa.philips.com/healthcare/product/HC1046964/actiwatch-spectrum-activitymonitor

AORD 2006. Directive 2006/25/EC of the European Parliament and of the Council of 5 April 2006 on the minimum health and safety requirements regarding the exposure of workers to risks arising from physical agents (artificial optical radiation) $\left(19^{\text {th }}\right.$ individual Directive within the meaning of Article 16(1) of Directive 89/391/EEC). OJ L 114, 27.4.2006, p. 38

http://eur-lex.europa.eu/legalcontent/EN/TXT/PDF/?uri=CELEX:02006L002520140101\&from $=\mathrm{EN}$

CHAMORRO, E.; Carralero, S.F.; Bonnin-Arias, C.; Pérez-Carrasco, M.J.; de Luna, J.M.; et al. 2013. Photoprotective effects of blue light absorbing filter against LED light exposure on human retinal pigment epithelial cells in vitro. J. Carcinog. Mutagen. S6:008, doi:10.4172/2157-2518. 
CIBSE 2016 / CRCE-RDD01-2016. HRLBL: Human Responses to Lighting Based on LED Lighting Solutions. The Chartered Institution of Building Services Engineers, Balham and Public Health England, Centre for Radiation Chemical and Environmental Hazards, Didcot.

CIE 2019. CIE Position Statement on the Blue Light Hazard (April 23, 2019) http://cie.co.at/publications/position-statement-blue-light-hazard-april-23-2019

HAM, W.T.; Mueller H.A. 1976. Retinal sensitivity to damage from short wavelength light. Nature 260, 153-155.

ICNIRP 1997. INTERNATIONAL COMMISSION ON NON-IONIZING RADIATION PROTECTION, 1997. Guidelines on Limits of Exposure to Broad-Band Incoherent Optical Radiation (0.38 to $3 \mu \mathrm{m})$. Health Physics 73 (3), 539-554.

ICNIRP 2004. INTERNATIONAL COMMISSION ON NON-IONIZING RADIATION PROTECTION, 2004. Guidelines on Limits of Exposure to Ultraviolet Radiation of Wavelengths between $180 \mathrm{~nm}$ and $400 \mathrm{~nm}$ (Incoherent Optical Radiation). Health Physics 87 (2), 171-186.

ICNIRP 2013. INTERNATIONAL COMMISSION ON NON-IONIZING RADIATION PROTECTION, 2013. Guidelines on Limits of Exposure to Incoherent Visible and Infrared Radiation. Health Physics 105(1), 74-96.

JAADANE, I.; Boulenguez, P.; Chahory, S.; Carré, S.; Savoldelli, M.; Jonet, L.; Behar-Cohen, F.; Martinsons, C.; Torriglia, A. 2015. Retinal damage induced by commercial light emitting diodes (LEDs). Free Radic. Biol. Med. 84, 373-384. doi:10.1016/j.freeradbiomed.2015.03.034.

O'HAGAN, J.B.; Khazova, M. and Price, L.L.A. 2016. Low-energy light bulbs, computers, tablets and the blue light hazard. Eye 30 (2), 230-233.

PRICE, L.L.A.; Khazova, M. and O'Hagan, J.B. 2012. Performance assessment of commercial circadian personal exposure devices, Light. Res. Technol. 44, 17-26.

SCHEER 2018. Scientific Committee on Health, Environmental and Emerging Risks (SCHEER). Opinion on Potential risks to human health of Light Emitting Diodes (LEDS) https://ec.europa.eu/health/sites/health/files/scientific_committees/scheer/docs/scheer_o _011.pdf

SLINEY, D. 1984. Quantifying retinal irradiance levels in light damage experiments. Curr. Eye Res. 3(1), 175-179.

SPARROW, J.R.; Miller A.S. and Zhou, J. 2004. Blue light-absorbing intraocular lens and retinal pigment epithelium protection in vitro. J. Cataract Refract. Surg. 30, 873-878.

UDOVICIC, L.; Janßen, M.; Nowack, D.; Price, L.L.A. 2016. Personenbezogene Lichtexpositionsmessungen in Feldstudien - Eine Handlungsanleitung zur Charakterisierung und Kalibrierung von Lichtexpositionsdetektoren, BAuA, Dortmund https://www.baua.de/DE/Angebote/Publikationen/Berichte/F2355.html

UDOVICIC, L. and Janßen, M. 2019. Photobiological safety of common office light sources. Proceedings of $29^{\text {th }}$ Quadrennial Session of the International Commission on Illumination (CIE), Washington, June 17-19, 2019; to be published 